\title{
The digital inclusion of older people in Spain: technological support services for seniors as predictor
}

\author{
Ramón Tirado-Morueta ${ }^{1 \star(D)}$, Alejandro Rodríguez-Martín² (D), Emilio Álvarez-Arregui², \\ Miguel Ángel Ortíz-Sobrino ${ }^{3}$ and José Ignacio Aguaded-Gómez ${ }^{1}$ \\ ${ }^{1}$ Department of Pedagogy, University of Huelva, Huelva, Spain, ${ }^{2}$ Department of Education Sciences, \\ University of Oviedo, Oviedo, Spain and ${ }^{3}$ Department of Journalism and New Media, Complutense \\ University of Madrid, Madrid, Spain \\ ${ }^{*}$ Corresponding author. Email: rtirado@uhu.es
}

(Accepted 15 July 2021)

\begin{abstract}
While life expectancy increases in developed countries and there is evidence that demonstrates the potential of the internet to optimise or compensate for the losses associated with ageing, there is a high proportion of older people who continue to be disconnected from the digital world. In this scenario, the technological support offered by public institutions has the potential to be an accessible source for the digital literacy of older people. This study, using the model of digital inequality, had the aim of analysing the ability of these institutional supports to determine and predict the digital inclusion of older people. The sample was retired adults (over 54 years) residing in Spain who are users of technological support services in four organisational contexts: nursing homes, senior community centres, University Programs for Seniors and adult education programmes. Through binary logistic regression analysis, we found that the ability of the availability of literacy support to determine and predict access, autonomy, skills and use of the internet for social connectivity depends on the social and organisational context of the technology support service. These findings support empirically the situated nature of technological support for the digital inclusion of older people and provide a useful comparative vision for the design of accessible support services adapted to the needs of its users.
\end{abstract}

Keywords: digital literacy, digital skills, digital divide, Internet access, older adults

\section{Introduction}

According to Eurostat's (2019a) data from 2005 to 2019, in the countries of the European Union, the growth of the population over 54 years of age is almost four times that of the general population. This ageing population poses

(C) The Author(s), 2021. Published by Cambridge University Press. This is an Open Access article, distributed under the terms of the Creative Commons Attribution-NonCommercial-NoDerivatives licence (http://creativecommons.org/ licenses/by-nc-nd/4.0/), which permits non-commercial re-use, distribution, and reproduction in any medium, provided the original work is unaltered and is properly cited. The written permission of Cambridge University Press must be obtained for commercial re-use or in order to create a derivative work. 
opportunities and challenges for the economy, and the health and social systems (Schulz et al., 2015).

Due to changes in employment status such as retirement, financial situation or loss of mobility and health problems, and loss of partners and friends due to death, social isolation is a problem for many older adults (Savikko et al., 2005). Data from longitudinal studies (Steptoe et al., 2013) and meta-analyses (Holt-Lunstad et al., 2013) indicate that social isolation is significantly associated with mortality. Perceived social isolation, often referred to as loneliness, can also be related to poor cognitive functioning and poorer mental and physical health (Cacioppo and Cacioppo, 2014).

The abundant evidence showing the adverse impacts on health and quality of life of social isolation and loneliness suggests the need to develop interventions to prevent or remedy it. In this sense, information and communication technologies (ICTs) have the potential to maintain or improve the social connectivity of older adults, as well as to compensate for the losses and deficits derived from ageing (Kamin et al., 2016). There are longitudinal studies that have analysed the benefits of internet use in older adults. For example, Kamin and Lang (2020) analysed representative data across 14 countries from the Survey of Health, Ageing and Retirement in Europe. The sample included 29,576 participants between 50 and 100 years of age, and found that using the internet positively affects cognitive functioning in late life. Cotten et al. (2014) used data from four waves (2002-2008) of the US Health and Retirement Survey including only people 50 years of age or older and retirees, and found that internet use reduces the probability of a depressive state by approximately 33 per cent and provided some evidence that the mechanism that relates internet use to depression is the remediation of social isolation and loneliness. In this sense, studies such as that by Czaja et al. (2018), through an experiment with people 65 years or older who lived alone in independent housing, suggest that access to technology applications may enhance social connectivity and reduce loneliness among older adults and has the potential to change attitudes towards technology and increase technology self-efficacy.

In developed countries, the number of older adults going online and using digital media over the past decades has increased steadily, however, many seniors remain relatively divorced from digital life (Anderson and Perrin, 2017; Eurostat, 2019b). This evidence suggests that the population over the age of 54, with respect to the general population, is a group that is vulnerable to digital exclusion, and is more likely to become isolated from societies where technology is increasingly present in public services and in private life (Friemel, 2016).

From the ecological model of ageing (Lawton and Nahemow, 1973), some authors argue that the contexts of ageing entail not only demands but also resources and opportunities that are relevant for personal growth and engagement in new experiences (Kamin et al., 2016). In this sense, recent studies (e.g. Friemel, 2016) underline the need for research to place more emphasis on analysing the support services that can assist older people in obtaining benefits and appropriating new media. Politically, The Global Strategy and Action Plan on Ageing and Health 2016-2020 (World Health Organization (WHO), 2016) recognises the capacity of centres for older people to promote social inclusion for the older population and establishes among its objectives to promote the development of courses and actions aimed at the proper use of ICTs. 
Trying to cover the lack of studies focused on support services promoted by public institutions for the digital integration of older people, this study aimed to identify the extent to which support services, from different organisational contexts, help retired adults to be digitally integrated. To do this, the authors took as a reference the theory of digital inequality (DiMaggio and Hargittai, 2001), since from this approach, support services, together with physical access, autonomy, skills and purposes of use, can be considered a relevant component associated with the digital integration of people.

\section{Background}

\section{Ageing and internet adoption}

Since the early 2000s, scholars have argued that 'there is a strong association between age and the so-called digital divide' (Selwyn, 2004; Neves and Amaro, 2012) and have coined the term 'grey divide' (Millward, 2003) to describe the lack of 'access, skills and/or knowledge that can result in older citizens being "information poor"' (Kania-Lundholm and Torres, 2015). However, research in this area has also received criticism for treating older adults as a homogenous group and neglecting the diversity in older adults' lives and how they use digital technologies (e.g. Rasi and Kilpeläinen, 2016).

Instead, there is evidence of factors associated with age - beyond income, education and gender (e.g. mistrust, low media literacy, physical and mental limitations) that continue to hamper their advantageous use of new media (Nimrod, 2017; Quan-Haase et al., 2018). For example, Wagner et al. (2010), in their review of the literature, found that computer use among older citizens varied significantly. Czaja et al. (2006) found that the relationship between age and adoption of technology was mediated by cognitive abilities, computer self-efficacy and computer anxiety. However, the study by Gell et al. (2013), using a representative sample of adults over 64 years of age in the United States of America (USA), showed that the prevalence of internet use differs according to socio-demographic status (younger age, male sex, white race, higher education level and being married) and type of disability and impairments that limit activity. Other studies have shown evidence of the influence of social support as a central mechanism that may facilitate the use of technology among older adults, especially among those with functional limitations (e.g. Kamin et al., 2019). In general, these results suggest a tendency to focus on the obstacles and facilities that can make it possible for older people to regulate their own social context with the help of technologies (Kamin et al., 2016).

\section{Digital inequality in older people}

As the pervasiveness of the internet in society increases, the access gap between rich and poor, urban and rural dwellers, old and young, or educated and uneducated people disappears. However, the dimensions related to the quality of use become important bases by which the benefits of technology are stratified (van Dijk, 2005, 2006). DiMaggio and Hargittai (2001) identified five dimensions on which digital inequality can be articulated among older people. 
The first refers to variation in the technical means (hardware and connections) by which people access the internet (van Deursen and van Dijk, 2018). The hypothesis is that an inferior technical device reduces the benefits that users can obtain from the internet, either because they cannot access certain sites or because their experience on the Web is less rewarding and they abandon. In a recent study by van Deursen and van Dijk (2018), within a representative sample in the Netherlands, they observed an inverse correlation with age in terms of the diversity of devices used. In any case, there is evidence to show that having diverse material access and frequent physical access does not guarantee beneficial results (van Deursen and Helsper, 2015).

The second is the variation in the extent to which people have autonomy when using the internet, e.g. if they access it from work or home, if their use is supervised or not, or if they must compete with other users for online time (Newhagen and Bucy, 2004; van Dijk, 2006). On the autonomy of internet access, there is evidence of the importance of quality access points for a beneficial use of the internet, as well as an association between the socio-educational status and the quality of internet access (Hassani, 2006).

The third is inequality in the skill that people bring to their use of the internet. As the access to resources among citizens is generally overcome, a third variation is defined in the skills required for a productive use of ICTs (e.g. Zillien and Hargittai, 2009; Witte and Mannon, 2010). Recent studies in advanced countries such as Denmark (van Boekel et al., 2017) and Germany (Schehl et al., 2019) have shown that older adults are a heterogeneous group, with various categories of internet users that are identified according to frequency, type and extent of use. However, other qualitative studies carried out in the USA (e.g. Heart and Kalderon, 2013) and Canada (Schreuers et al., 2017) showed that the range of activities conducted by older adults through technology is limited; so that their skills will be limited in the context of these activities, reducing the range of (digital) activities that could benefit their lives. This is what Schreuers et al. (2017) named the digital skills bubble, where some activities and skills are very familiar, while others are not. Thus, and according to these authors, in order for these limitations to be overcome, the bubble will have to expand, so that older adults improve their skills. But this can only occur if they have more opportunities and social support to try to use ICTs (Francis et al., 2018).

The fourth is inequality in the support available to internet users. There are numerous studies that have attempted to understand the training and support needed to encourage digital literacy for older adults (e.g. Sayago et al., 2011; Hardill and Olphert, 2012; Barnard et al., 2013; Friemel, 2016; Rasi and Kilpeläinen, 2016; Quan-Haase et al., 2017; Hunsaker et al., 2019). In general, digital literacy is acquired through experience, which goes beyond basic exposure to technology (Murray and Pérez, 2014). Among older people, social support family and friends - constitute some of the main stimuli and sources of literacy for internet use (Friemel, 2016). However, the support given can lack immediacy, leaving older adults dependent on others' availability to provide it (Hunsaker et al., 2019). In this sense, qualitative studies have found that older people may prefer to opt for formal sources of support (Seo et al., 2019), due to the burden it may entail (Peek et al., 2016) or the feeling of dependency on one's own family (Schreurs 
et al., 2017). Hunsaker et al. (2019), based on in-depth qualitative interviews with a multinational sample of older adults, explored the support needs of older adults in the use of digital media and concluded that educational approaches that emphasise individualised support and wide availability could allow an enhanced experience tailored to a diverse range of interests.

The fifth is variation in the purposes for which people use technology. The regulation of social contexts entails a number of challenges for older adults. The lifespan theoretical model of selection, optimisation and compensation (Baltes and Baltes, 1990) is useful for understanding the purposes of older people when using the internet. From the outset of selection, some argue that it is essential for good ageing to use technology proactively in order to shape social contexts in accordance with age-specific needs and goals (Rohr and Lang, 2009). Socio-emotional selectivity serves as an example - that is, when feeling near to the end of life, older adults proactively engage in those relationships that they perceive as meaningful in their life (Carstensen et al., 1999). The qualitative study by Melenhorst et al. (2006) concluded that although cost can be an obstacle for older adults in selecting an online activity, the absence of benefit is more likely to be the key factor. For example, Gatto and Tak (2008) reported that perceived benefits of internet use among older adults were primarily associated with opportunities for social interaction, despite the obstacles they had to face. Nimrod (2013) suggested that older adults selectively participated in interactions that were in accordance with their emotional and psychosocial needs, which may be helpful in addressing age-related challenges in the areas of health, family and retirement. The optimisation principle refers to the role of technology to improve regulation of the social contexts of older people. There is empirical evidence that ICTs in old age are not only used for the compensation of loss (e.g. isolation, infrequent contact) but also for the optimisation and improvement of contact (e.g. Hogeboom et al., 2010; Smith, 2014; Rainie and Zickuhr, 2015). Finally, the compensation principle refers to the ways in which technology is used to cope with the experiences of loss associated with ageing. For example, in a longitudinal study with Japanese older adults, researchers found that cell phone use reduces depression in older women (Minagawa and Saito, 2014).

\section{Technology support services for seniors (TSSS)}

Inequality in the opportunities to access internet-based services and to benefit from their use reflects how public and institutional policies are responding to the challenge of universal internet access (Garnham, 1997). In order to compensate for differences in internet access among older citizens, experts and international organisations have proposed the promotion of universal internet access for the population through TSSS (Lacruz and Galofré, 2011; WHO, 2016). Kamin et al. (2016) define TSSS as community-based services promoted by public institutions to facilitate material access to the internet and literacy support for older people. Likewise, these services can attend to diverse social contexts and be located in different organisational contexts. For example, in Spain, universities have done this through programmes such as the University Programs for Seniors, facilitating internet use by, and digital literacy for, older adults through courses. Likewise, within the 
formal education system in Spain, adult education programmes also develop media and digital literacy courses. Other public policies have installed publicly owned telecentre networks that aim to facilitate and streamline internet access through networked telecentres and libraries, from senior centres and nursing homes (Alcalá, 2014).

Previous studies on the effectiveness of TSSS have shown that physical access to the internet is insufficient if it is not linked to digital training programmes (Millward, 2003; Morris, 2007; European Commission, 2010). Therefore, promoting access opportunities implies making the necessary resources available to older people to facilitate internet use and to enable them to obtain benefits (Sourbati, 2009). For example, the training programmes from Older Adults Technology Services, a non-profit organisation based in New York City, supported the selective shaping of social contexts by optimising resources and by providing means to compensate potential risks (e.g. isolation, lack of support). The participants used more communication tools (e.g. email, texting), which allowed them to create new opportunities for enhanced contact (Kamin et al., 2016).

The results of empirical studies that have examined the adoption of new ICTs by older people have highlighted the importance of social relationships in shaping access to technologies (Warschauer, 2003), and suggest that internet access should be situated locally, within particular organisational and community contexts, and adapted to the rhythm of the users (Seo et al., 2017). Community workers in public libraries, senior centres or nursing homes can facilitate or constrain internet access (Sourbati, 2009).

\section{Research questions}

First, from the perspective of the DiMaggio and Hargittai (2001) model, digital inequality can be articulated around technical means, autonomy of access, digital skills, social supports and purposes of use. TSSS sponsored by government agencies and local governments can play an important role in shaping older people's social contexts and their digital inclusion (Kamin et al., 2016). Therefore, the success of these services may be linked to their adaptation to older people's social contexts. According to Lawton's (1989) ecological framework, contextual resources can be used successfully when they are adjusted to the heterogeneous needs and capacities of older adults. There is empirical evidence that suggests that TSSS should be adjusted to the community context in which they operate (Warschauer, 2003; Seo et al., 2019). Therefore, given the heterogeneity of social and organisational contexts of the TSSS, two research questions (RQ) were raised:

- RQ1: To what extent do the socio-demographic characteristics of TSSS users and literacy support determine and predict the availability of (a) technical means to access the internet, (b) autonomy of access, (c) digital skills, and (d) use of the internet for social connectedness?

- RQ2: To what extent does the social and organisational context of the TSSS condition the ability of the availability of literacy support to determine and predict the availability of (a) technical means to access the internet, (b) autonomy of access, (c) skills, and (d) internet use for social connectedness? 


\section{Methodology}

\section{Participants}

In order to respond to the research questions, we considered four types of TSSS used by retired adults in Spain. The participants were retired adults ( $>54$ years) who used the internet - at least once in the previous 3 months - and were regular users of TSSS. The TSSS were situated in four organisational contexts:

- Nursing homes $(\mathrm{NH})$, which are homes or establishments in which social support activities are developed for older people through collective housing; temporary or permanent use that includes food, health care, hygiene and comfort, promoting co-existence and leisure time for elderly residents. Participating $\mathrm{NH}$ had classrooms with internet access and held computer workshops regularly.

- Senior community centres (SCC), which are non-residential social services facilities intended to promote co-existence among older people, encouraging participation and social integration. They offer sociocultural, occupational, artistic and recreational activities. These centres house classrooms with computers and internet access, and computer workshops are held regularly.

- University Programs for Seniors (UPS), which arose in the 1970s, were designed to improve the basic skills of older adults in order to promote their social and cultural participation and personal development (Villar et al., 2010). UPS offer digital literacy workshops.

- Adult education programmes (AEP), in which formal educational plans are offered to obtain the official Compulsory Secondary Education diploma. They also offer non-formal education plans. In their educational plans, subjects in the field of communication are offered.

In the absence of reliable data concerning the population of older adults attending these TSSS, we conducted non-probability quota sampling to obtain a similar number of subjects in each TSSS. The authors established quotas of 140 adults over 54 and internet users in the four types of organisational context $(\mathrm{N}=560)$. The selection of the centres and participants was random among the users of the four TSSS in three cities of autonomous communities which have a low, medium and high per capita income and ageing index (INEbase, 2019a, 2019b): Huelva, Asturias and Madrid. Although the systems are not mutually exclusive (one user can be a user of multiple supports), the participants were exclusive users of one of them.

In order to obtain an unbiased sample within the same type of TSSS, our team of researchers administered a maximum of five questionnaires with the prior authorisation of the entity's administrator. We administered the questionnaires during the third week of October 2018.

The mean age of the respondents was 67.78 years old. Broken down by type of context, the mean age of the respondents in NH was 73.28, in SCC 69.74, in UPS 63.98 and in AEP 63.91. Regarding gender, 56.7 per cent were female, 56.4 per cent being female in NH, 55.6 per cent in SCC, 64.0 per cent in UPS and 50.4 per cent in AEP. 


\section{Measurements}

In response to the research questions, we controlled for variables relating to the demographic characteristics of the sample (age, gender and co-existence) and socioeconomic status (educational level and monthly income). Researchers in the area of digital inequality have found that age, gender, education and income are associated with internet use (e.g. van Deursen and van Dijk, 2018) and with capital-enhancing activities and digital skills (Hargittai and Dobransky, 2017). Covariates included chronological age, re-codified into a categorical variable with three categories based on the retirement age (55-64, 65-74 and over 74 years of age), gender (female and male), co-existence (alone and accompanied), educational level (primary, secondary and tertiary studies) and monthly income, taking as a reference the pension bracket in Spain (less than €600, €601-1,200, €1,201-1,800 and more than $€ 1,800$ ).

In order to measure the literacy support received from the TSSS, the Eurostat (2019c) scale was used, with values from 1 (never) to 4 (very frequently). This scale measured the degree of support provided by the institution's educators to older people in order to learn to use the internet $(\alpha=0.95)$. The variable literacy support was the mean value of the responses of the respondents to all the items on the scale.

To operationalise the dimensions of digital inequality (DiMaggio and Hargittai, 2001), we used the following measures:

- Technical means refer to the availability of adequate equipment to carry out a given online activity (van Deursen and van Dijk, 2018): we used a dichotomous scale (no $=0$, yes $=1$ ) to ask the respondents for the number of internet access devices (smartphone, tablet, laptop, desktop computer, others). The variable technical means was the sum of the responses (minimum $=1$ and maximum $=5$ ).

- Autonomy to access the internet refers to the freedom to use technology when and where one wants without constraint from others, such as lines of library patrons or employer supervision (Hargittai and Hinnant, 2008; Hargittai and Dobransky, 2017). We used a dichotomous scale (no $=0$, yes $=1$ ) to assess the number of places from where the respondent accessed the internet at least once a week (home, the street, social centres, educational centres and community services). Finally, the variable autonomy of access was the sum of the places of access reported by the respondents (minimum $=1$ and maximum $=5$ ).

- Digital skills refer to skills that enable users to derive the full benefits that access can provide (Hargittai and Hinnant, 2008). To measure the digital skills, we used a synthesis of the scale by Goldhammer et al. (2013) - skills for access, management and dissemination of information - related to basic skills, with values from 1 (not true) to 4 (completely true) $(\alpha=0.95)$. The digital skills variable was the mean value of the responses to each item.

- Purpose of social connectedness refers to the need for psychological connection with others and to create positive human interaction (Schulz et al., 2015). The search for social connectedness is based on the evidence that sustains that older people use the internet to interact socially, either for reasons of 
emotional selectivity (e.g. Nimrod, 2013), to optimise their social contacts (e.g. Hogeboom et al., 2010; Smith, 2014; Rainie and Zickuhr, 2015) or to compensate for the losses derived from ageing (e.g. Minagawa and Saito, 2014). We used a selection of items from the scales used by Papacharissi and Rubin (2000) - $\alpha$ values greater than 0.78 - and by $\mathrm{Ku}$ et al. (2013) $-\alpha$ values greater than 0.85 - on the gratifications obtained through the use of the internet, with values of 1 (disagree) to 4 (totally agree). The variable purpose of social connectedness was the mean value of the responses of the respondents to all the items on the scale.

Table A1 in the Appendix includes more details about each scale's wording and descriptive results as well as the convergent validity of the variables analysed (average variance, factorial loading, composite reliability and Cronbach's alpha of each scale).

\section{Data analysis}

In order to answer the research questions, we used sequential binary logistic regression (BLR). The primary objective of this technique is to model how categorical variables influence the probability of occurrence of a dichotomous event. To avoid the problem derived from having categorical predictors with limited cases in each category, we ran descriptive statistics on each of their predictors and we contracted categories. We also made a diagnosis of multicollinearity, which verified that socio-demographic variables and literacy support were not strongly related, showing tolerance values higher than 1 and Variance Inflation Factor lower than 10. Finally, our research team verified outliers or cases that are not well explained by their model. For this, we specified the residuals and eliminated the outliers.

This study will seek to identify the variables that predict the probability of belonging or not to a singular cluster in four types of TSSS (i.e. NH, SCC, UPS and AEP). The dependent variables were technical means $(0=$ just one access device, $1=$ more than one $)$, autonomy of access $(0=$ up to two access points, $1=$ more than two), digital skills ( $0=$ up to the 75 th percentile, $1=$ above the 75 th percentile) and social connectedness ( $0=$ up to the 75 th percentile, $1=$ above the 75 th percentile).

We sequentially included two blocks of independent variables in the models: (a) the socio-demographic characteristics of TSSS users and (b) the frequency of literacy support. The socio-demographic variables were age (55-64, 65-74 and over 74), gender (female and male), co-existence (alone or accompanied), educational level (primary, secondary or university) and monthly income (up to $€ 1,200$ or more than $€ 1,200$ ). We then categorised the level of support received for digital literacy into tertiles (Tertiles 1, 2 and 3), with Tertile 3 representing a level of support greater than two-thirds of the respondents.

Table 1 shows the distribution of the respondents among the different categories of the dependent and independent variables in the four organisational contexts. It is noteworthy that in general terms UPS users tend to be younger and of mediumhigh socio-economic status. $\mathrm{NH}$ and AEP users tend to have a medium-low socioeconomic level. SCC users are usually older and of an upper-middle level. In addition, it should be noted that the older users are found in NH and SCC. Regarding 
Table 1. Descriptive analysis

\begin{tabular}{|c|c|c|c|c|c|}
\hline & Total sample & $\mathrm{NH}$ & SCC & UPS & AEP \\
\hline & \multicolumn{5}{|c|}{ Frequencies (\%) } \\
\hline \multicolumn{6}{|l|}{ Age: } \\
\hline $55-64$ & $194(35.6)$ & $8(5.8)$ & $33(24.1)$ & $78(56.5)$ & $75(56.8)$ \\
\hline $65-74$ & $235(42.0)$ & $72(52.2)$ & $70(51.1)$ & $46(33.3)$ & $47(35.6)$ \\
\hline$>74$ & $116(20.7)$ & $58(42.0)$ & $34(24.8)$ & $14(10.1)$ & $10(7.6)$ \\
\hline \multicolumn{6}{|l|}{ Gender: } \\
\hline Female & $304(54.3)$ & $75(56.4)$ & $75(55.6)$ & $89(64.0)$ & $65(50.4)$ \\
\hline Male & $232(41.4)$ & $58(43.6)$ & $60(44.4)$ & $50(36.0)$ & $64(49.6)$ \\
\hline \multicolumn{6}{|l|}{ Co-existence: } \\
\hline Alone & $130(24.0)$ & $25(18.1)$ & $38(27.9)$ & $35(25.4)$ & $32(24.6)$ \\
\hline Accompanied & $412(76.0)$ & $113(81.9)$ & $98(72.1)$ & $103(74.6)$ & $98(75.4)$ \\
\hline \multicolumn{6}{|l|}{ Educational level: } \\
\hline Primary & $183(32.7)$ & $69(50.0)$ & $33(24.1)$ & $20(14.4)$ & $61(44.9)$ \\
\hline Secondary & $195(34.8)$ & $38(27.5)$ & $56(40.9)$ & $62(44.6)$ & $39(28.7)$ \\
\hline Tertiary & $172(30.7)$ & $31(22.5)$ & $48(35.0)$ & $57(41.0)$ & $36(26.5)$ \\
\hline \multicolumn{6}{|l|}{ Income: } \\
\hline Up to $€ 1,200$ & $348(62.1)$ & $101(72.1)$ & $81(57.9)$ & 47 (33.6) & $119(85.0)$ \\
\hline Over $€ 1,200$ & $212(37.9)$ & $39(27.9)$ & $59(42.1)$ & $93(66.4)$ & $21(15.0)$ \\
\hline \multicolumn{6}{|l|}{ Digital literacy support: } \\
\hline Tertile 1 & $175(31.3)$ & $29(23.6)$ & $63(49.2)$ & $19(15.4)$ & $19(15.4)$ \\
\hline Tertile 2 & $140(25.0)$ & $37(30.1)$ & $29(22.7)$ & $28(22.2)$ & $46(37.4)$ \\
\hline Tertile 3 & $185(33.0)$ & $57(46.3)$ & $38(28.1)$ & $34(27.0)$ & $58(47.2)$ \\
\hline \multicolumn{6}{|l|}{ Technical means: } \\
\hline One device & $187(33.4)$ & $55(40.1)$ & $58(43.3)$ & $32(23.0)$ & $42(30.4)$ \\
\hline More than one device & $361(64.5)$ & $82(59.9)$ & $76(56.7)$ & $107(77.0)$ & $96(69.6)$ \\
\hline \multicolumn{6}{|l|}{ Autonomy: } \\
\hline Up to two access points & $252(45.0)$ & $85(70.2)$ & $65(67.0)$ & $43(39.8)$ & $59(47.2)$ \\
\hline More than two access points & $199(35.5)$ & $36(29.8)$ & $32(33.0)$ & $65(60.2)$ & $66(52.8)$ \\
\hline \multicolumn{6}{|l|}{ Digital skill: } \\
\hline Less than Tertile 3 & $399(71.3)$ & $100(74.1)$ & $115(83.9)$ & $75(56.0)$ & $109(82.0)$ \\
\hline Tertile 3 & $140(25.0)$ & $35(25.9)$ & $22(16.1)$ & $59(44.0)$ & $24(18.0)$ \\
\hline \multicolumn{6}{|l|}{ Purpose of social connectedness: } \\
\hline Less than Tertile 3 & $370(66.1)$ & $96(69.6)$ & $101(72.1)$ & $78(56.1)$ & $95(68.8)$ \\
\hline Tertile 3 & $185(33.0)$ & $42(30.4)$ & $39(27.9)$ & $61(43.9)$ & $43(31.2)$ \\
\hline
\end{tabular}

Notes: NH: nursing homes. SCC: senior community centres. UPS: University Programs for Seniors. AEP: adult education programmes. 
the provision of literacy support, it should be noted that TSSS users in contexts with a lower socio-economic status (i.e. NH and AEP) reported that they had more support available than in other contexts (i.e. UPS and SCC).

\section{Results}

In order to respond to RQ1a-d (Table 2), we performed a sequenced BLR to assess the impact of (a) socio-demographic characteristics and (b) digital literacy support on the likelihood that respondents report that they were digitally included (i.e. they have more than one access device, more than two access points, have a high level of skill and use the internet for social contactedness).

Regarding RQ1a, the data showed that the youngest respondents with secondary education, tertiary education and income above $€ 1,200$ are more likely to have more than one mobile device for internet access than people with a primary education and lower income. When we incorporated the literacy support variable into the model, the fit of the model improved and the variance increased slightly. In addition, the data showed that the probability of having more than one internet access device was higher among respondents who frequently had digital literacy support in NH, UPS and AEP.

Regarding RQ1b, the data showed that older respondents (older than 74 years) were less likely to have more than one internet access point than younger ones. In the second step, the incorporation of the literacy support variable in the model improved the fit of the model, the classification of the respondents and slightly increased the variance. Furthermore, the data showed that the probability of autonomy is notably higher among UPS users who frequently had literacy support.

Regarding RQ1c, in the first step, the model had a better fit and a better classification of the respondents than in the previous models. The data showed that respondents with higher incomes and with secondary and university education are more likely to have high abilities than those with only primary education. However, in the second step, incorporating the availability of digital literacy support into the model markedly improved the fit, the classification of cases and increased the variance. The results showed that respondents who frequently had digital literacy support at NH and UPS were more likely to have high digital skills than the rest of the respondents. In addition, the availability of support reduced the probability due to educational level. In other words, it made up for the lack of academic training.

Regarding RQ1d, the data showed that male respondents, with a higher level of education and higher income, are more likely to use the internet for the purpose of connecting with other people than the rest of the respondents. In the second step, we included literacy support in the model and the goodness of fit improved, the variance increased significantly and the case classification improved. The data showed that respondents who had more frequent literacy support were more likely to use the internet to interact socially.

Regarding RQ2a (Table 3), the availability of various internet access devices depended more strongly on the socio-demographic characteristics in the SCC. In contrast, in the UPS, the determination of socio-demographic characteristics was very low. Likewise, users with a higher education level were more likely to have 
Table 2. Binomial logistic regression (regarding Research Question 1a-d)

(a) Technical means

(b) Autonomy

(c) Skills

(d) Social connectedness

$\operatorname{Exp}(B)$ values

Age group (Ref. 55-64):

\begin{tabular}{|c|c|c|c|c|c|c|c|c|}
\hline $65-74$ & 0.78 & 1.03 & $0.56^{\star \star}$ & 0.71 & 0.87 & 0.78 & 1.32 & 1.51 \\
\hline$>74$ & $0.43^{\star \star}$ & 0.59 & $0.25^{\star \star \star}$ & $0.23^{\star \star \star}$ & 0.59 & 0.43 & 0.57 & 0.63 \\
\hline \multicolumn{9}{|c|}{ Gender (Ref. Female): } \\
\hline Male & 1.13 & 1.11 & 0.96 & 1.08 & 1.29 & 1.28 & $1.53^{*}$ & $1.72^{\star}$ \\
\hline \multicolumn{9}{|c|}{ Live alone or accompanied (Ref. alone): } \\
\hline Accompanied & 1.07 & 1.01 & 0.67 & 0.65 & 1.21 & 1.17 & 0.99 & 0.91 \\
\hline \multicolumn{9}{|c|}{ Educational level (Ref. Primary): } \\
\hline Secondary & $1.64^{\star}$ & $1.87^{\star}$ & 0.74 & 0.73 & $14.89^{\star \star \star}$ & $3.04^{\star *}$ & $2.59^{\star \star}$ & $2.43^{\star \star}$ \\
\hline Tertiary & $2.70^{\star \star \star}$ & $3.01^{\star \star \star}$ & 1.04 & 1.21 & $21.82^{\star \star \star}$ & $5.56^{\star \star \star}$ & $3.01^{\star \star \star}$ & $2.95^{\star \star \star}$ \\
\hline \multicolumn{9}{|c|}{ Income (Ref. $\leqslant € 1,200$ ): } \\
\hline$>€ 1,200$ & $2.47^{\star \star \star}$ & $2.94^{\star \star \star}$ & 1.04 & 0.87 & $2.60^{\star \star \star *}$ & $2.05^{\star}$ & $1.59^{\star}$ & 1.38 \\
\hline
\end{tabular}

Digital literacy support in NH (Ref. In

other TSSS):

\begin{tabular}{llll} 
Tertile 1 & 1.10 & 0.38 & 0.62 \\
\hline Tertile 2 & $2.69^{*}$ & 0.60 & 0.68 \\
\hline Tertile 3 & $3.68^{\star \star *}$ & 0.76 & 0.67 \\
\hline $\begin{array}{l}\text { Digital literacy support in SSC (Ref. In } \\
\text { other TSSS): }\end{array}$ & & $2.53^{\star}$ \\
Tertile 1 & 1.10 & $0.31^{*}$ & 1.04 \\
\hline
\end{tabular}




\begin{tabular}{|c|c|c|c|c|c|c|c|c|}
\hline Tertile 2 & & 0.77 & & 0.50 & & 0.21 & & 0.41 \\
\hline Tertile 3 & & 1.67 & & 0.73 & & 1.02 & & 2.28 \\
\hline \multicolumn{9}{|c|}{$\begin{array}{l}\text { Digital literacy support in UPS (Ref. In } \\
\text { other TSSS): }\end{array}$} \\
\hline Tertile 1 & & 2.42 & & 0.61 & & 1.84 & & 0.60 \\
\hline Tertile 2 & & 1.35 & & 1.43 & & 1.57 & & 2.25 \\
\hline Tertile 3 & & $6.17^{\star *}$ & & $10.28^{\star \star \star}$ & & $12.40^{\star \star \star}$ & & $4.19^{\star \star}$ \\
\hline \multicolumn{9}{|c|}{$\begin{array}{l}\text { Digital literacy support in AEP (Ref. In } \\
\text { other TSSS): }\end{array}$} \\
\hline Tertile 1 & & 2.78 & & 1.49 & & 0.72 & & 0.31 \\
\hline Tertile 2 & & $4.64^{\star \star}$ & & 0.57 & & 0.23 & & 0.16 \\
\hline Tertile 3 & & $5.15^{\star \star \star}$ & & 1.01 & & $3.00^{\star}$ & & $2.88^{\star}$ \\
\hline Nagelkerke $R^{2}$ & 0.16 & 0.25 & 0.08 & 0.21 & 0.30 & 0.38 & 0.13 & 0.28 \\
\hline$\Delta$ Nagelkerke $R^{2}$ & & 0.09 & & 0.13 & & 0.08 & & 0.15 \\
\hline Hosmer and Lemeshow test $(p)$ & $3.07(0.92)$ & $4.34(0.82)$ & $5.77(0.67)$ & $6.83(0.55)$ & $11.22(0.18)$ & $10.22(0.24)$ & $5.56(0.69)$ & $3.13(0.91)$ \\
\hline Omnibus tests - chi-square & $63.30^{\star \star \star}$ & $101.02^{\star \star \star}$ & $27.08^{\star \star \star}$ & $71.16^{\star \star \star}$ & $106.34^{\star \star \star}$ & $147.92^{\star \star \star}$ & $50.41^{\star \star}$ & $116.05^{\star \star \star}$ \\
\hline Percentage of classification & 69.3 & 73.01 & 59.2 & 66.9 & 77.1 & 80.07 & 68.4 & 72.6 \\
\hline
\end{tabular}

Notes : Ref.: reference category. TSSS: technology support services for seniors. NH: nursing home. SCC: senior community centres. UPS: University Programs for Seniors. AEP: adult education programmes.

Significance levels: ${ }^{\star} p<0.05,{ }^{\star \star} p<0.01,{ }^{\star \star \star} p<0.001$. 
Table 3. Binomial logistic regression (regarding Research Question 2a)

\begin{tabular}{|c|c|c|c|c|c|c|c|c|}
\hline & \multicolumn{2}{|c|}{ Nursing home } & \multicolumn{2}{|c|}{ Senior community centres } & \multicolumn{2}{|c|}{$\begin{array}{l}\text { University Programs for } \\
\text { Seniors }\end{array}$} & \multicolumn{2}{|c|}{$\begin{array}{l}\text { Adult education } \\
\text { programmes }\end{array}$} \\
\hline & \multicolumn{8}{|c|}{$\operatorname{Exp}(B)$ values } \\
\hline \multicolumn{9}{|l|}{ Age group (Ref. 55-64): } \\
\hline $65-74$ & 1.82 & 1.16 & 0.71 & 0.96 & 0.74 & 0.83 & 0.77 & 0.44 \\
\hline$>74$ & 0.81 & 0.61 & $0.23^{\star}$ & 0.29 & 1.70 & 1.16 & .65 & 1.03 \\
\hline \multicolumn{9}{|l|}{ Gender (Ref. Female): } \\
\hline Male & 0.57 & 0.48 & 0.96 & 0.85 & 1.43 & 1.30 & 1.94 & $3.91^{\star}$ \\
\hline \multicolumn{9}{|c|}{ Live alone or accompanied (Ref. Alone): } \\
\hline Accompanied & 1.29 & .51 & 1.80 & 1.61 & 0.97 & 1.33 & 0.59 & 0.85 \\
\hline \multicolumn{9}{|l|}{ Educational level (Ref. Primary): } \\
\hline Secondary & $4.39^{\star \star}$ & $4.37^{\star \star}$ & $3.26^{\star}$ & $3.85^{\star}$ & 0.76 & 0.63 & 1.44 & 1.36 \\
\hline Tertiary & $4.82^{\star \star}$ & $4.55^{\star}$ & $5.39^{\star *}$ & $6.48^{\star \star}$ & 1.32 & 1.09 & 2.27 & 1.50 \\
\hline \multicolumn{9}{|l|}{ Income (Ref. $\leqslant € 1,200$ ): } \\
\hline$>€ 1,200$ & 1.55 & 1.47 & 1.80 & $3.58^{\star}$ & 1.95 & $3.12^{\star}$ & 7.06 & - \\
\hline \multicolumn{9}{|c|}{ Digital literacy support (Ref. Tertile 1): } \\
\hline Tertile 2 & & $4.18^{\star}$ & & 0.65 & & 0.42 & & 2.20 \\
\hline Tertile 3 & & $4.99^{\star}$ & & 1.28 & & 1.65 & & 2.86 \\
\hline Nagelkerke $R^{2}$ & 0.24 & 0.28 & 0.35 & 0.36 & 0.08 & 0.16 & 0.18 & 0.28 \\
\hline$\Delta$ Nagelkerke $R^{2}$ & & 0.05 & & 0.01 & & 0.08 & & 0.10 \\
\hline Hosmer and Lemeshow test $(p)$ & $6.25(0.51)$ & $7.83(0.45)$ & $6.18(0.62)$ & $2.30(0.97)$ & $5.07(0.74)$ & $3.19(0.92)$ & $3.24(0.91)$ & $6.36(0.60)$ \\
\hline Omnibus tests - chi-square & $25.19^{\star \star}$ & $26.45^{\star \star}$ & $37.32^{\star \star \star}$ & $34.68^{\star \star \star}$ & 7.13 & 13.18 & $15.99^{*}$ & $21.28^{\star}$ \\
\hline Percentage of classification & 73.6 & 74.6 & 71.3 & 73.9 & 76.9 & 81.3 & 70.1 & 79.2 \\
\hline
\end{tabular}

Notes: Ref.: reference category. Dependent variable: technical means ( $0=$ one device; $1=$ more than one device)

Significance levels: ${ }^{\star} p<0.05,{ }^{\star \star} p<0.01,{ }^{\star \star \star} p<0.001$. 
Table 4. Binomial logistic regression (regarding Research Question 2b)

\begin{tabular}{|c|c|c|c|c|c|c|c|c|}
\hline & \multicolumn{2}{|c|}{ Nursing home } & \multicolumn{2}{|c|}{ Senior community centres } & \multicolumn{2}{|c|}{$\begin{array}{l}\text { University Programs for } \\
\text { Seniors }\end{array}$} & \multicolumn{2}{|c|}{$\begin{array}{l}\text { Adult education } \\
\text { programmes }\end{array}$} \\
\hline & \multicolumn{8}{|c|}{ Exp(B) values } \\
\hline $65-74$ & 2.19 & 1.90 & 0.60 & 0.45 & 0.74 & 0.94 & 0.69 & 0.53 \\
\hline$>74$ & 0.52 & 0.44 & $0.04^{\star \star}$ & $0.04^{*}$ & 3.03 & 1.02 & 0.29 & 0.30 \\
\hline \multicolumn{9}{|l|}{ Gender (Ref. Female): } \\
\hline \multicolumn{9}{|c|}{ Live alone or accompanied (Ref. Alone): } \\
\hline Accompanied & 0.61 & 0.44 & 0.57 & 0.34 & 1.28 & 1.65 & 0.52 & 0.71 \\
\hline \multicolumn{9}{|l|}{ Educational level (Ref. Primary): } \\
\hline Secondary & 1.60 & 1.18 & 1.53 & 1.41 & 0.50 & 0.41 & 0.49 & 0.36 \\
\hline Tertiary & 0.73 & 0.60 & 3.02 & 2.65 & 0.75 & 0.74 & 1.46 & 1.38 \\
\hline Tertile 2 & & 1.84 & & 1.24 & & 2.01 & & 0.33 \\
\hline Tertile 3 & & 2.34 & & 1.52 & & $9.51^{\star \star}$ & & 0.67 \\
\hline Nagelkerke $R^{2}$ & 0.15 & 0.17 & 0.24 & 0.28 & 0.09 & 0.25 & 0.11 & 0.14 \\
\hline$\Delta$ Nagelkerke $R^{2}$ & & 0.02 & & 0.04 & & 0.16 & & 0.03 \\
\hline Hosmer and Lemeshow test $(p)$ & $12.57(0.08)$ & $10.75(0.21)$ & $5.34(0.72)$ & $6.52(0.58)$ & $5.85(0.66)$ & $2.36(0.93)$ & $12.20(0.09)$ & $10.18(0.25)$ \\
\hline Omnibus tests - chi-square & 12.65 & 13.11 & $15.65^{\star}$ & $17.64^{*}$ & 7.07 & 20.38 & 9.35 & 10.33 \\
\hline Percentage of classification & 69.6 & 63.5 & 72.7 & 73.8 & 61.0 & 69.4 & 55.7 & 61.3 \\
\hline
\end{tabular}


Table 5. Binomial logistic regression (regarding Research Question 2c)

\begin{tabular}{|c|c|c|c|c|c|c|c|c|}
\hline & \multicolumn{2}{|c|}{ Nursing home } & \multicolumn{2}{|c|}{ Senior community centres } & \multicolumn{2}{|c|}{$\begin{array}{l}\text { University Programs for } \\
\text { Seniors }\end{array}$} & \multicolumn{2}{|c|}{$\begin{array}{l}\text { Adult education } \\
\text { programmes }\end{array}$} \\
\hline & \multicolumn{8}{|c|}{$\operatorname{Exp}(B)$ values } \\
\hline \multicolumn{9}{|l|}{ Age group (Ref. 55-64): } \\
\hline $65-74$ & 2.86 & 2.19 & 1.02 & 1.30 & 0.60 & 0.62 & 0.85 & 0.64 \\
\hline$>74$ & 1.10 & 0.91 & 0.32 & 0.50 & 1.47 & 0.54 & 1.23 & 2.24 \\
\hline \multicolumn{9}{|l|}{ Gender (Ref. Female): } \\
\hline \multicolumn{9}{|c|}{ Live alone or accompanied (Ref. Alone): } \\
\hline Accompanied & 1.59 & 0.51 & 1.97 & 1.99 & 1.38 & 1.52 & 1.07 & 1.27 \\
\hline \multicolumn{9}{|l|}{ Educational level (Ref. Primary): } \\
\hline Secondary & $4.63^{\star \star}$ & $5.75^{\star}$ & 2.60 & 3.45 & 4.25 & $5.39^{*}$ & 1.63 & 1.15 \\
\hline Tertiary & 2.37 & 1.76 & 4.89 & 4.54 & $7.73^{\star}$ & $11.62^{\star \star}$ & $4.39^{*}$ & $4.28^{\star}$ \\
\hline Tertile 2 & & 1.14 & & 0.26 & & 0.90 & & 0.38 \\
\hline Tertile 3 & & $34.11^{\star \star}$ & & 1.23 & & $7.46^{\star \star}$ & & 5.74 \\
\hline Nagelkerke $R^{2}$ & 0.20 & 0.51 & 0.26 & 0.29 & 0.14 & 0.29 & 0.18 & 0.32 \\
\hline$\Delta$ Nagelkerke $R^{2}$ & & 0.31 & & 0.03 & & 0.15 & & 0.14 \\
\hline Hosmer and Lemeshow test $(p)$ & $5.96(0.54)$ & $14.30(0.07)$ & $6.39(0.60)$ & $7.21(0.51)$ & $8.87(0.35)$ & $6.16(0.62)$ & $12.54(0.12)$ & $5.54(0.69)$ \\
\hline Omnibus tests - chi-square & $19.39^{*}$ & $50.30^{\star \star \star}$ & $20.07^{\star *}$ & $50.63^{\star \star \star}$ & $14.52^{*}$ & $28.68^{\star \star}$ & 13.83 & $22.32^{\star \star}$ \\
\hline Percentage of classification & 73.8 & 85.6 & 84.8 & 84.2 & 65.1 & 70.3 & 86.6 & 82.5 \\
\hline
\end{tabular}


Table 6. Binomial logistic regression (regarding Research Question 2d)

\begin{tabular}{|c|c|c|c|c|c|c|c|c|}
\hline & \multicolumn{2}{|c|}{ Nursing home } & \multicolumn{2}{|c|}{ Senior community centres } & \multicolumn{2}{|c|}{$\begin{array}{l}\text { University Programs for } \\
\text { Seniors }\end{array}$} & \multicolumn{2}{|c|}{$\begin{array}{l}\text { Adult education } \\
\text { programmes }\end{array}$} \\
\hline & \multicolumn{8}{|c|}{ Exp(B) values } \\
\hline $65-74$ & 3.95 & 3.74 & 1.31 & 1.64 & 1.83 & $2.99^{\star}$ & 0.57 & $0.16^{*}$ \\
\hline$>74$ & 1.11 & 0.92 & 0.27 & 0.52 & 1.56 & 0.76 & 0.44 & 0.84 \\
\hline \multicolumn{9}{|l|}{ Gender (Ref. Female): } \\
\hline \multicolumn{9}{|c|}{ Live alone or accompanied (Ref. Alone): } \\
\hline Accompanied & 1.73 & 1.12 & 0.61 & 0.58 & 1.02 & 1.24 & 1.38 & 1.77 \\
\hline \multicolumn{9}{|l|}{ Educational level (Ref. Primary): } \\
\hline Secondary & $7.36^{\star \star \star}$ & $7.28^{\star \star}$ & 0.59 & 0.62 & 1.30 & 1.41 & 1.96 & 2.55 \\
\hline Tertiary & 2.86 & 2.49 & 2.86 & 2.19 & 0.94 & 1.52 & $3.33^{*}$ & $5.41^{\star}$ \\
\hline Tertile 2 & & 1.05 & & 1.45 & & $3.96^{\star}$ & & 1.82 \\
\hline Tertile 3 & & $4.19^{*}$ & & $8.81^{\star \star}$ & & $8.73^{\star * *}$ & & $41.24^{\star \star}$ \\
\hline Nagelkerke $R^{2}$ & 0.25 & 0.35 & 0.22 & 0.32 & 0.09 & 0.28 & 0.20 & 0.54 \\
\hline$\Delta$ Nagelkerke $R^{2}$ & & 0.10 & & 0.10 & & 0.19 & & 0.34 \\
\hline Hosmer and Lemeshow test $(p)$ & $4.10(0.76)$ & $13.86(0.08)$ & $8.32(0.20)$ & $8.09(0.42)$ & $3.05(0.93)$ & $8.76(0.36)$ & $7.16(0.51)$ & $13.38(0.09)$ \\
\hline Omnibus tests - chi-square & $25.70^{\star \star}$ & $38.64^{\star \star \star}$ & $19.42^{\star \star}$ & $29.41^{\star \star}$ & 8.87 & $28.65^{\star \star}$ & $18.09^{*}$ & $49.37^{\star \star \star}$ \\
\hline Percentage of classification & 74.4 & 78.8 & 72.7 & 82.1 & 61.9 & 72.4 & 74.1 & 85.0 \\
\hline
\end{tabular}

Notes: Ref.: reference category. Dependent variable: social connectedness ( $0=$ up to Quartile 3; $1=$ Quartile 4). Significance levels: ${ }^{\star} p<0.05,{ }^{* \star} p<0.01,{ }^{\star \star *} p<0.001$. 
more than one device for internet access, both in SCC and NH. In the second step, including the availability of digital literacy support in the models slightly increased the explained variance in all TSSS. Only among NH users did the availability of literacy support significantly increase the probability that older adults had more than one internet access device.

With respect to RQ2b (Table 4), in the first step, the variance of the autonomy of internet access varied between the different types of TSSS, being again higher in SCC. In other words, the socio-demographic characteristics affected autonomy of access, especially in SCC. In the second step, the availability of literacy support was included in the models by heterogeneously increasing the explained variance of autonomy. In the UPS alone, people who frequently had digital literacy support were much more likely to have multiple internet access points.

Regarding RQ2c (Table 5), in the first step, socio-demographic characteristics more strongly determined digital skills in SCC and NH. Likewise, users with a higher educational level were more likely to have high digital skills, both in $\mathrm{NH}$, as in UPS and AEP. In contrast, in SCC, people with higher incomes were more likely to have a high level of digital skills. In the second step, the introduction of the availability of digital literacy support markedly increased the fit of all models and the determination of high digital skills in NH, UPS and AEP. The frequent availability of digital literacy support increased the likelihood of TSSS users having high skills, especially at UPS and NH.

Regarding RQ2d (Table 6), in the first step, the variance of internet use for social connectivity was heterogeneous between TSSS, being strong in NH, SCC and AEP, and weaker in UPS. Likewise, while in NH it was more likely that the older adults with secondary education used the internet frequently to interact socially, in AEP it was also more likely in people with incomes above $€ 1,200$. In the second step, when including the availability of digital literacy support in the models, the explained variance of frequent internet use for social connectivity purposes increased in all TSSS. Likewise, the availability of digital literacy support increased the probability that older people use the internet frequently to interact with other people in all services, and more strongly in AEP.

\section{Discussion}

Although there is evidence that supports the potential of the internet to optimise the wellbeing of older people or compensate for their losses - physical, emotional or social - associated with ageing (Kamin et al., 2016), a high percentage of older adults continue to be disconnected from the digital world (Eurostat, 2019c). In order to help older people to benefit from the resources of the digital world, both international organisations (e.g. WHO, 2016) and the scientific community (e.g. Kamin et al., 2016; Seo et al., 2019) have begun to focus on formal technology support services.

In this sense, case studies have shown the social benefits of community technology support services (e.g. Kamin et al., 2016). These services, promoted by public institutions (social institutes, universities, educational systems, city councils, etc.), usually develop training actions adjusting to the needs of their users and the social context. A recent study of older Americans (Hargittai et al., 2018) revealed 
considerable variation in internet knowledge associated with socio-economic status, suggesting the need to consider socio-economic status in any formal measure of support. As in previous studies carried out in Spain (Tirado-Morueta, et al., 2020), in this study we found that technological support services serve a population with diverse socio-demographic characteristics depending on the social and organisational context. In this sense, we found that: (a) users of UPS tend to be younger and have a higher socio-economic level; (b) users of $\mathrm{NH}$ tend to be the oldest and with the lowest socio-economic status; (c) users of SCC tend to be older but with a higher socio-economic status; and (d) users of AEP tend to be younger but have low status.

The general data from our study showed that socio-demographic characteristics determine to a different extent the dimensions of digital inclusion of older people, having a special influence on the availability of material means and skills. Similar to previous studies (Hargittai and Dobransky 2017; Hargittai et al., 2018), those participants that were the youngest, with higher education and income were more likely to have more access devices and higher digital skills. However, regarding access autonomy, age was the main determinant, with the youngest being the ones who were more likely to have multiple internet access points.

However, we observed a heterogeneous determination according to the organisational context. In this sense, we observed that the determination of sociodemographic characteristics was lower in organisational contexts whose users are younger and their disconnection with working life is recent (i.e. UPS and AEP). According to other findings (Francis et al., 2018), users closest to their previous work stage would be expected to maintain relationships that provide informal support (e.g. family, friends, former colleagues, etc.) that compensate for differences due to socio-economic status.

Regarding the capacity of literacy support to determine and predict the digital inclusion of older people, the results of the total sample showed that the availability of literacy support explained better than socio-demographic factors the variance of high digital skills and use of the internet for social connectedness. Therefore, in general, the data suggest that this type of formal support is more a source of literacy than a place of internet access in a society in which the gap in material access is gradually closing (Schulz et al., 2015). But the ability of the availability of literacy support to influence skills and communication is not the same in all technology support services, being especially high in NH and UPS.

Therefore, given the evidence of the capacity of social and organisational contexts to condition the influence of technological support (Kamin et al, 2016), we detail the findings below.

\section{Regarding technical means}

The socio-educational level of the users determined the probability of having several internet access devices, especially in residences and senior centres, where the average age of the users is higher and they are more likely to have less social support that balances differences due to educational status (e.g. Kamin et al., 2019). Similar to the findings of Kamin et al. (2019) in their NH study, the frequent availability of actual support increased the likelihood of having various technical devices. But in 
addition, the data from the current study suggest that the availability of technical support could balance the gaps in the availability of technical means due to age, economic situation and gender.

\section{Regarding autonomy of access}

In three of the organisational contexts (NH, SCC, AEP), the autonomy to access the internet was mainly determined by the age of the users. Especially in the SCC, as the age group increased, the probability that users would access the internet from more than two access points decreased. However, among users of UPS, the frequent availability of support markedly increased the likelihood that users would have multiple internet access points. In line with other findings that highlight the quality of access points as a factor that explains the gap in internet use (Hassani, 2006), these results could be due to the multiple access points where older people access the internet and that they are supported in university contexts, such as libraries, classrooms, colleges, computer rooms or Wi-Fi on campus.

\section{Regarding digital skills}

The general results showed that users of technological support services with higher educational and economic status were more likely to have high digital skills. However, in organisational contexts with younger users - UPS and AEP - their determination was lower, possibly due to the fact that they tend to have more social and informal supports that balance differences due to status (Hunsaker et al., 2019).

Regarding the determination of support, users who frequently had support increased their probability of having a high level of digital skills. This was especially pronounced both in $\mathrm{NH}$ - users with low socio-economic status, and in UPS - users with high status. These results reinforce the postulates that support services present not only as a resource to compensate for deficits (e.g. Seo et al., 2019) but also as a source to optimise skills, i.e. although users of UPS tend to have more skills than those of the other services, they can find in these supports a source to resolve their doubts (Hunsaker et al., 2019) or improve their social conditions (Kamin et al., 2016).

Likewise, both in NH and UPS, controlling for the availability of literacy supports increased the probability that users with a higher level of studies would have higher skills, suggesting that the availability of support may help balance differences due to educational attainment.

\section{Regarding social connectedness purpose}

In general, it was more likely that internet users seeking social connectivity would be found among men with higher educational and economic status, although a high frequency of literacy support severely increased this probability, helping to balance differences due to status and gender.

Similar to previous findings (Shapira et al., 2007), it is worth highlighting the ability of the frequency of support to compensate for differences - due to age and educational level - regarding the use of the internet as a means of social connectedness. On the one hand, among users of UPS, frequent literacy support could 
increase the probability that those over 74 years of age will use the internet to interact with other people. On the other hand, in AEP, the high availability of support reduced the gap due to educational status.

The ability of the availability of support to determine the purpose of the internet use among younger users suggests that they seek support to optimise their social relationships rather than to compensate for the losses associated with ageing (Kamin et al., 2016). However, it is necessary to delve into the motivations that encourage users to use the internet and consider them in the organisation of this type of service, as well as in the modelling of formal support services associated with ageing (Hunsaker et al., 2019).

\section{Conclusions}

Initiatives that recognise the usefulness of technological support promoted by public institutions to help older people connect to the digital world and benefit from the use of the internet are increasingly frequent. The data from this study, in general, using a sample of users of technological support services in four organisational contexts - NH, SCC, UPS and AEP - showed that when older people frequently have access to literacy support then this increases the likelihood of having high digital skills and taking advantage of the internet to connect socially.

However, the results suggest that the social and organisational context conditions the capacity of literacy support to determine and anticipate other more basic dimensions - material access and autonomy of access - for the digital inclusion of older people. For example, the availability of technical means and autonomy to access the internet were mainly determined by socio-educational status. However, in contexts where users tend to be older and have a low socio-educational status, such as residences for older people, the availability of frequent support also stimulated the probability of having more than one device to access the internet.

In line with other results, the availability of technological support determines a high percentage of the variance of digital skills, both in organisational contexts where users have a low socio-educational status (i.e. $\mathrm{NH}$ ) and in contexts whose users have a high socio-educational status (i.e. UPS). These data suggested that depending on the socio-demographic characteristics of the users of these services, the availability of support will have a different meaning for its users, either as a source for the acquisition of basic skills or as a resource to optimise their abilities.

Furthermore, contrary to what might be assumed, it was in organisational contexts with younger users (i.e. UPS and AEP) that the availability of support most strongly determined the probability of using the internet to connect socially. In other words, although younger users tend to have more informal social supports, formal supports are also a source for them to optimise their social connectivity.

The results of the analyses showed the importance of frequently having formal supports as a source of skills and social use of the internet, compensating - in some cases - for differences due to age and socio-educational status. Likewise, evidence suggests that the capacity of technological support services to determine the digital inclusion of the older people is conditioned by their social and organisational context. This study provides inputs for the design of technological support services 
adjusted to the characteristics and needs of the social and organisational context where they operate.

\section{Limitations and future studies}

In order to guide future research, some of the study limitations should be considered. One of the limitations of the study is the use of self-administered questionnaires. In this sense, it is advisable to delve into this topic using qualitative data collection and analysis techniques (e.g. Quan-Haase et al., 2018; Hunsaker et al., 2019).

Likewise, it would be interesting to consider an assessment of the needs (e.g. functional limitations or social isolation) of older adults and their social supports. Furthermore, further studies could focus on other types of organisational contexts and disadvantaged social contexts associated with ageing (e.g. Seo et al., 2019), taking into account the various didactic and organisational aspects and including the teachers' and social workers' perspectives.

Acknowledgments. Funding for open access charge: University of Huelva.

Financial support. This work was conducted within the framework of 'Alfamed' (Euro-American Network of Researchers), with the support of the R+D Project 'Youtubers and Instagrammers: Media Competence in Emerging Prosumers' (RTI2018-093303-B-I00), financed by the State Research Agency of the Spanish Ministry of Science, Innovation and Universities and the European Regional Development Fund.

Conflict of interest. The authors declare no conflicts of interest.

\section{References}

Alcalá LA (2014) Media literacy for older people facing the digital divide: the e-inclusion programmes design. Comunicar: Media Education Research Journal 42, 173-180.

Anderson M and Perrin A (2017) Tech Adoption Climbs Among Older Adults. Pew Research Center. Available at http://www.pewinternet.org/2017/05/17/tech-adoption-climbs-among-older-adults/.

Baltes PB and Baltes MM (1990) Psychological perspectives on successful aging: the model of selective optimization with compensation. In Baltes PB and Baltes MM (eds), Successful Aging: Perspectives from the Behavioral Sciences. New York, NY: Cambridge University Press, pp. 1-34.

Barnard Y, Bradley MD, Hodgson F and Lloyd AD (2013) Learning to use new technologies by older adults: perceived difficulties, experimentation behavior and usability. Computers in Human Behavior 29, 1715-1724.

Cacioppo JT and Cacioppo S (2014) Social relationships and health: the toxic effects of perceived social isolation. Social and Personality Psychology Compass 8, 58-72.

Carstensen LL, Isaacowitz DM and Charles ST (1999) Taking time seriously: a theory of socioemotional selectivity. American Psychologist 54, 165-181.

Cotten SR, Ford G, Ford S and Hale TM (2014) Internet use and depression among retired older adults in the United States: a longitudinal analysis. Journals of Gerontology: Psychological Sciences and Social Sciences 69B, 763-771.

Czaja SJ, Charness N, Fisk AD, Hertzog C, Nair SN, Rogers WA and Sharit J (2006) Factors predicting the use of technology: findings from the Center for Research and Education on Aging and Technology Enhancement (CREATE). Psychology and Aging 21, 333-352.

Czaja SJ, Boot WR, Charness N, Rogers WA and Sharit J (2018) Improving social support for older adults through technology: findings from the PRISM randomized controlled trial. The Gerontologist 58, 467-477. 
DiMaggio P and Hargittai E (2001) From the 'digital divide' to 'digital inequality': studying Internet use as penetration increases. Center for Arts and Cultural Policy Studies, Woodrow Wilson School, Princeton University, Princeton, NJ, Working Paper 15.

European Commission (2010) Study on the Social Impact of ICT. Available at http://ec.europa.eu/information_society/eeurope/i2010/docs/eda/social_impact_of_ict.pdf.

Eurostat (2019a) Individuals - Frequency of Internet Use. Brussels: European Commission. Available at https://appsso.eurostat.ec.europa.eu/nui/show.do?dataset=isoc_ci_ifp_fu\&lang=en.

Eurostat (2019b) Individuals - Internet Activities. Brussels: European Commission. Available at https:// appsso.eurostat.ec.europa.eu/nui/show.do?dataset=isoc_ci_ac_i\&lang=en.

Eurostat (2019c) Individuals' Level of Internet Skills. Brussels: European Commission. Available at https:// appsso.eurostat.ec.europa.eu/nui/show.do?dataset=isoc_sk_iskl_i\&lang=en.

Francis J, Kadylak T, Makki TW, Rikard RV and Cotten SR (2018) Catalyst to connection: when technical difficulties lead to social support for older adults. American Behavioral Scientist 62, 1167-1185.

Friemel TN (2016) The digital divide has grown old: determinants of a digital divide among seniors. New Media \& Society 18, 313-331.

Garnham N (1997) Amartya Sen's 'capabilities' approach to the evaluation of welfare: its application to communications. Javnost - The Public 4, 25-34.

Gatto SL and Tak SH (2008) Computer, Internet, and e-mail use among older adults: benefits and barriers. Educational Gerontology 34, 800-811.

Gell NM, Rosenberg DE, Demiris G, LaCroix AZ and Patel KV (2013) Patterns of technology use among older adults with and without disabilities. The Gerontologist 55, 412-421.

Goldhammer F, Naumann J and Keßel Y (2013) Assessing individual differences in basic computer skills. European Journal of Psychological Assessment 29, 263-275.

Hardill I and Olphert CW (2012) Staying connected: exploring mobile phone use amongst older adults in the UK. Geoforum 43, 1306-1312.

Hargittai E and Dobransky K (2017) Old dogs, new clicks: digital inequality in skills and uses among older adults. Canadian Journal of Communication 42, 195-212.

Hargittai E and Hinnant A (2008) Digital inequality: differences in young adults' use of the Internet. Communication Research 35, 602-621.

Hargittai E, Piper AM and Morris MR (2018) From Internet access to Internet skills: digital inequality among older adults. Universal Access in the Information Society 18, 881-890.

Hassani SN (2006) Locating digital divides at home, work, and everywhere else. Poetics 34, 250-272.

Heart T and Kalderon E (2013) Older adults: are they ready to adopt health-related ICT? International Journal of Medical Informatics 82, e209-e231.

Hogeboom DL, McDermott RJ, Perrin KM, Osman H and Bell-Ellison BA (2010) Internet use and social networking among middle aged and older adults. Educational Gerontology 36, 93-111.

Holt-Lunstad J, Smith TB and Layton JB (2013) Social relationships and mortality risk: a meta-analytic review. PLOS Medicine 7, e1000316.

Hunsaker A, Nguyen MN, Fuchs J, Djukaric T, Hugentobler L and Hargittai E (2019) 'He explained it to me and I also did it myself: how older adults get support with their technology uses. Socius: Sociological Research for a Dynamic World 4. Available at https://doi.org/10.1177/2378023119887866.

INEbase (2019a) Renta media por persona. Madrid: Instituto Nacional de Estadística. Available at https:// www.ine.es/jaxiT3/Datos.htm?t=9947.

INEbase (2019b) Índice de envejecimiento por provincias. Madrid: Instituto Nacional de Estadística. Available at https://www.ine.es/jaxiT3/Datos.htm?t=1489.

Kamin ST and Lang FR (2020) Internet use and cognitive functioning in late adulthood: longitudinal findings from the Survey of Health, Ageing and Retirement in Europe (SHARE). Journals of Gerontology: Psychological Sciences and Social Sciences 75B, 534-539.

Kamin ST, Lang FR and Kamber T (2016) Social contexts of technology use in old age. In Kwon S (ed.), Gerontechnology: Research, Practice, and Principles in the Field of Technology and Aging. New York, NY: Springer, pp. 35-56.

Kamin ST, Beyer A and Lang FR (2019) Social support is associated with technology use in old age. Zeitschrift für Gerontologie und Geriatrie 53, 256-262.

Kania-Lundholm M and Torres S (2015) The divide within: older active ICT users position themselves against different 'Others'. Journal of Aging Studies 35, 26-36. 
Ku YC, Chu TH and Tseng CH (2013) Gratifications for using CMC technologies: a comparison among SNS, IM, and e-mail. Computers in Human Behavior 29, 226-234.

Lacruz MDCA and Galofré MC (2011) Sociedades digitales y nuevas alfabetizaciones: políticas públicas de inclusión y alfabetización digital. In Cabezudo Rodríguez N (ed.), Inclusión digital: perspectivas y experiencias. Zaragoza, Spain: Prensas Universitarias de Zaragoza, pp. 253-274.

Lawton MP (1989) Behavior-relevant ecological factors. In Schaie KW and Schooler C (eds), Social Structure and Aging: Psychological Processes. Hillsdale, NJ: Lawrence Erlbaum Associates, pp. 57-78.

Lawton MP and Nahemow L (1973) Ecology and the aging process. In Eisdorfer C and Lawton MP (eds), The Psychology of Adult Development and Aging. Washington, DC: American Psychological Association, pp. 619-674.

Melenhorst AS, Rogers WA and Bouwhuis DG (2006) Older adults' motivated choice for technological innovation: evidence for benefit-driven selectivity. Psychology and Aging 21, 190-195.

Millward P (2003) The 'grey digital divide': perception, exclusion and barriers of access to the Internet for older people. First Monday 8. Available at https://doi.org/10.5210/fm.v8i7.1066.

Minagawa Y and Saito Y (2014) An analysis of the impact of cell phone use on depressive symptoms among Japanese elders. Gerontology 60, 539-547.

Morris A (2007) E-literacy and the grey digital divide: a review with recommendations. Journal of Information Literacy 1, 13-28.

Murray MC and Pérez J (2014) Unraveling the digital literacy paradox: how higher education failed at the fourth literacy. Issues in Informing Science and Information Technology 11, 85-100.

Neves BB and Amaro F (2012) Too old for technology? How the elderly of Lisbon use and perceive ICT. Journal of Community Informatics 8. Available at https://doi.org/10.15353/joci.v8i1.3061.

Newhagen JE and Bucy EP (2004) Routes to media access. In Bucy EP and Newhagen JE (eds), Media Access: Social and Psychological Dimensions of New Technology Use. Mahwah, NJ: Lawrence Erlbaum Associates, pp 3-23.

Nimrod G (2013) Probing the audience of seniors' online communities. Journals of Gerontology: Psychological Sciences and Social Sciences 68B, 773-782.

Nimrod G (2017) Older audiences in the digital media environment. Information, Communication \& Society 20, 233-249.

Papacharissi Z and Rubin AM (2000) Predictors of Internet use. Journal of Broadcasting \& Electronic Media 44, 175-196.

Peek STM, Wouters EJ, Luijkx KG and Vrijhoef HJ (2016) What it takes to successfully implement technology for aging in place: focus groups with stakeholders. Journal of Medical Internet Research 18, e98.

Quan-Haase A, Mo GY and Wellman B (2017) Connected seniors: how older adults in East York exchange social support online and offline. Information, Communication \& Society 20, 967-983.

Quan-Haase A, Williams C, Kicevski M, Elueze I and Wellman B (2018) Dividing the grey divide: deconstructing myths about older adults' online activities, skills, and attitudes. American Behavioral Scientist 62, 1207-1228.

Rainie L and Zickuhr K (2015) Americans' Views on Mobile Etiquette (Research report). Available at http:// www.pewinternet.org/2015/08/26/americans-views-on-mobile-etiquette/.

Rasi P and Kilpeläinen A (2016) Older people's use and learning of new media: a case study on remote rural villages in Finnish Lapland. In Zhou J and Salvendy G (eds), International Conference on Human Aspects of IT for the Aged Population. Cham, Switzerland: Springer, pp 239-247.

Rohr MK and Lang FR (2009) Aging well together - a mini-review. Gerontology 55, 333-343.

Savikko N, Routasalo P, Tilvis RS, Strandberg TE and Pitkälä KH (2005) Predictors and subjective causes of loneliness in an aged population. Archives of Gerontology and Geriatrics 41, 223-233.

Sayago S, Sloan D and Blat J (2011) Everyday use of computer-mediated communication tools and its evolution over time: an ethnographical study with older people. Interacting with Computers 23, 543-554.

Schehl B, Leukel J and Sugumaran V (2019) Understanding differentiated internet use in older adults: a study of informational, social, and instrumental online activities. Computers in Human Behavior 97, 222-230.

Schreuers K, Quan-Haase A and Martin K (2017) Problematizing the digital literacy paradox in the context of older adults' ICT use: aging, media discourse, and self-determination. Canadian Journal of Communication 42, 359-377.

Schulz R, Wahl HW, Matthews JT, De Vito Dabbs A, Beach SR and Czaja SJ (2015) Advancing the aging and technology agenda in gerontology. The Gerontologist 55, 724-734. 
Selwyn N (2004) Reconsidering political and popular understandings of the digital divide. New Media o Society 6, 341-362.

Seo H, Erba J, Geana M and Lumpkins C (2017) Calling Doctor Google? Technology adoption and health information seeking among low-income African-American older adults. Journal of Public Interest Communications 1, 153-173.

Seo H, Erba J, Altschwager D and Geana M (2019) Evidence-based digital literacy class for older, lowincome African-American adults. Journal of Applied Communication Research 47, 130-152.

Shapira N, Barak A and Gal I (2007) Promoting older adults' well-being through Internet training and use. Aging \& Mental Health 11, 477-484.

Smith A (2014) Older Adults and Technology Use (Research report). Available at http://www.pewinternet. org/files/2014/04/PIP_Seniors-andTech-Use_040314.pdf.

Sourbati M (2009) 'It could be useful, but not for me at the moment': older people, internet access and e-public service provision. New Media \& Society 11, 1083-1100.

Steptoe A, Shankar A, Demakakos P and Wardle J (2013) Social isolation, loneliness, and all-cause mortality in older men and women. Proceedings of the National Academy of Sciences of the USA 110, 57975801.

Tirado-Morueta R, Aguaded-Gómez JI, Ortíz-Sobrino MA, Rodríguez-Martín A, Álvarez-Arregui E (2020) Determinants of social gratifications obtained by older adults mo-derated by public supports for Internet access in Spain. Telematics and Informatics 49, 101363. https://doi.org/10.1016/j.tele.2020. 101363

van Boekel LC, Peek ST and Luijkx KG (2017) Diversity in older adults' use of the internet: identifying subgroups through latent class analysis. Journal of Medical Internet Research 19, e180.

van Deursen AJ and Helsper EJ (2015) The third-level digital divide: who benefits most from being online? Communication and Information Technologies Annual (Studies in Media and Communications) 10, 29-52.

van Deursen AJ and van Dijk JA (2018) The first-level digital divide shifts from inequalities in physical access to inequalities in material access. New Media \& Society 21, 354-375.

van Dijk JA (2005) The Deepening Divide: Inequality in the Information Society. Thousand Oaks, CA: Sage. van Dijk JA (2006) Digital divide research, achievements and shortcomings. Poetics 34, 221-235.

Villar F, Pinazo S, Triadó C, Celdrán M and Solé C (2010) Older people's university students in Spain: a comparison of motives and benefits between two models. Ageing \& Society 30, 1357-1372.

Wagner N, Hassanein K and Head M (2010) Computer use by older adults: a multi-disciplinary review. Computers in Human Behavior 26, 870-882.

Warschauer M (2003) Demystifying the digital divide. Scientific American 289, 42-47.

Witte JC and Mannon SE (2010) The Internet and Social Inequalities. New York, NY: Routledge.

World Health Organization (WHO) (2016) The Global Strategy and Action Plan on Ageing and Health 2016-2020: Towards a World in Which Everyone Can Live a Long and Healthy Life: Resolution (No. A69/A/CONF./8). Geneva: WHO.

Zillien N and Hargittai E (2009) Digital distinction: status specific types of internet usage. Social Science Quarterly 90, 274-291. 


\section{Appendix}

Table A1. Descriptive results and validity and reliability properties of the scales

\begin{tabular}{|c|c|c|c|c|c|c|c|}
\hline Constructs & Items & Reference & Mean (SD) & Load & $\begin{array}{l}\text { Cronbach's } \\
\text { alpha }\end{array}$ & $\mathrm{CR}$ & AVE \\
\hline \multirow[t]{5}{*}{ Digital skill } & I know how to open a webpage & \multirow{5}{*}{$\begin{array}{l}\text { Goldhammer et al. } \\
\text { (2013) }\end{array}$} & $2.81(1.01)$ & 0.801 & 0.95 & 0.94 & 0.75 \\
\hline & $\begin{array}{l}\text { I know how to open downloaded } \\
\text { files }\end{array}$ & & $2.79(0.96)$ & 0.929 & & & \\
\hline & I know how to send an attachment & & $2.78(1.01)$ & 0.913 & & & \\
\hline & I know how to find information & & $2.69(0.96)$ & 0.825 & & & \\
\hline & I know how to share multimedia & & $2.48(1.07)$ & 0.864 & & & \\
\hline \multirow[t]{4}{*}{$\begin{array}{l}\text { Purpose of social } \\
\text { connectedness }\end{array}$} & I know how to connect with people & $\begin{array}{l}\text { Papacharissi and } \\
\text { Rubin (2000) }\end{array}$ & $2.24(0.99)$ & 0.837 & 0.92 & 0.92 & 0.68 \\
\hline & I know how to belong to a group & $\begin{array}{l}\text { Papacharissi and } \\
\text { Rubin (2000) }\end{array}$ & $1.98(0.95)$ & 0.832 & & & \\
\hline & $\begin{array}{l}\text { I know how to keep in contact with } \\
\text { family and friends }\end{array}$ & Ku et al. (2013) & $2.31(0.99)$ & 0.897 & & & \\
\hline & $\begin{array}{l}\text { I know how to organise social } \\
\text { events }\end{array}$ & Ku et al. (2013) & $2.45(1.05)$ & 0.838 & & & \\
\hline
\end{tabular}


